the corneal lamellae. Hence the pitting-representing isolated losses of tissue scarcely to be compared with the extensive and obvious destruction of tissue, that may spread through the greater part of the conjunctiva.

Concerning epithelial downgrowth 'generally in these cases, I should like to suggest two possible influences:-

1. On the whole it may be accepted that there was very little indication of epithelial activity in the Indian pits. There is no doubt at all that in some cases the pits remained entirely free from epithelial accumulation. I suggest that the explanation may lie in the fact that a very large proportion of our wandering patients had had little or no previous skilled treatment of their trachoma. There had been nothing to stimulate epithelial growth.

The average trachoma case in Brazil at the present day may receive the stimulus of fairly early and regular active (? caustic) treatment. Hence possibly the epithelial response as seen in Busacca's sections:

2. If my suggestion of the origin of the pits immediately below (not beneath) basal epithelial crypts should prove to be correct, the final epithelial proliferation should vary with the size of the original crypts. The larger and deeper the crypt the freer the epithelial response.

\title{
CASE OF BILATERAL EPITHELIOMA OF THE LIMBUS IN A BOY OF FIVE
}

BY

\section{A. Hugh LOWTHER}

MALAYAN MEDICAL SERVICE

THE following case is worthy of record on account of the early age of onset, and of the simultaneous involvement of both eyes.

A Tamil boy, aged 5 years, first attended the Ophthalmic Department of Penang General Hospital on March 3, 1932, complaining of lacrimation, photophobia, and discharge from both eyes.

He had a severe conjunctivitis, and there was dense scarring involving practically the whole of both corneae.

The parents gave a history indicating that he had had an acute conjunctivitis four years previously, which they themselves had treated with "Nantiwalam" (a tropical flower, the juice of 
which, I am told, is commonly used by these people for inflammations of the eye). The treatment was followed by the formation of extensive corneal capacities, and the eyes had been inflamed and troublesome ever since.

The boy continued to attend for some days, and treatment evidently produced some amelioration of symptoms, as he did

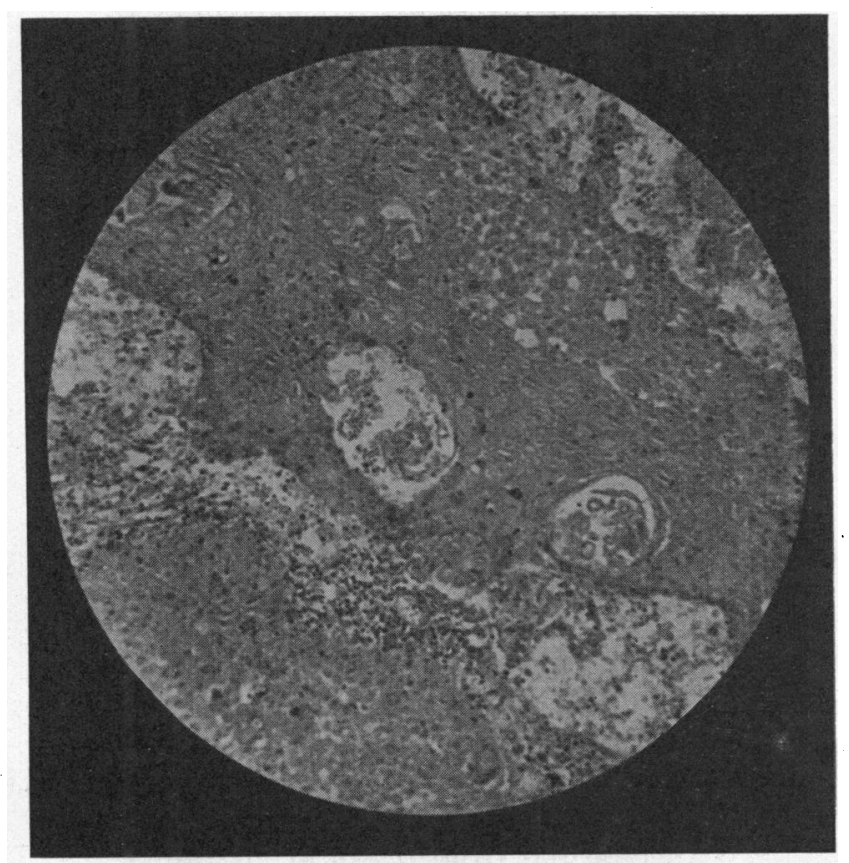

Enlargement of micro-photograph of tumour of right eye.

not attend again until November, when he returned with the same complaints as before.

On this occasion there was to be seen, in each eye, a greyish, raised, wart-like growth. The growths had overhanging edges and were symmetrically situated astride the limbus on the temporal side and in the horizontal diameter of each cornea. That of the right eye was the size of a three-penny bit, and that of the left slightly larger.

The tumour of the right eye was excised and sent for histological examination to Dr. Cowan, the Government Pathologist, who reported epithelioma.

Early in December, under general anaesthesia, the tumour of the left eye was excised and the base thoroughly cauterized with the 
galvano-cautery. The site of the tumour of the right eye was cauterized at the same time.

The pathologist's report on the second tumour was again epithelioma.

The boy was discharged from hospital on January 9, 1933, and was seen again in August of the same year just before I left Penang.

There was no evidence of a recurrence. The condition evidently resulted from the long-standing chronic inflammatory condition.

I am indebted to Dr. J. C. Tull, Government Pathologist, Singapore, for the excellent micro-photographs. 